\title{
Entrevista a Maria Helena da Cruz Coelho
}

Maria Helena da Cruz Coelho - an Interview

\section{Maria Helena da Cruz Coelho}

\section{(2) OpenEdition}

\section{Journals}

Edição electrónica

URL: http://journals.openedition.org/medievalista/1568

DOI: 10.4000/medievalista.1568

ISSN: 1646-740X

\section{Editora}

Instituto de Estudos Medievais - FCSH-UNL

\section{Edição impressa}

Data de publição: 1 Janeiro 2018

\section{Refêrencia eletrónica}

Maria Helena da Cruz Coelho, «Entrevista a Maria Helena da Cruz Coelho », Medievalista [Online], 23 | 2018, posto online no dia 07 maio 2018, consultado no dia 06 maio 2019. URL : http:// journals.openedition.org/medievalista/1568; DOI : 10.4000/medievalista.1568

Este documento foi criado de forma automática no dia 6 Maio 2019

(C) IEM 


\section{Entrevista a Maria Helena da Cruz Coelho}

Maria Helena da Cruz Coelho - an Interview

\section{Maria Helena da Cruz Coelho}

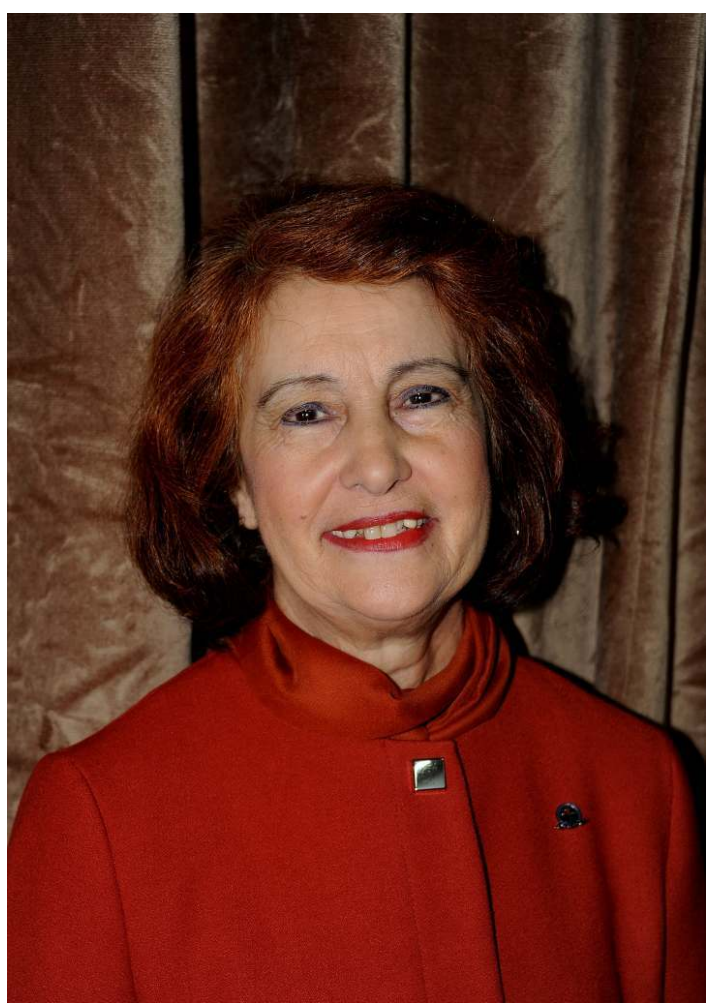

1 Catedrática de História Medieval na Faculdade de Letras da Universidade de Coimbra, Maria Helena da Cruz Coelho aposentou-se há cerca de um ano. Foi este o pretexto para uma entrevista à Presidente da Sociedade Portuguesa de Estudos Medievais, passando em revista um extenso e prestigiado percurso académico que é parte importante de um percurso de vida - da própria, mas também da instituição universitária e dos estudos 
medievais entre nós. Alvo de diversas homenagens, a nossa entrevistada deixa aqui inúmeros elementos de reflexão sobre o passado, o presente e o futuro da investigação e do ensino da Idade Média.

2 Com respostas claras a perguntas frontais, Maria Helena da Cruz Coelho (MHCC) revela uma vez mais a disponibilidade e a ponderação que lhe é reconhecida e que, a par da sua obra e do seu magistério, fazem dela uma figura de referência no panorama académico e historiográfico português.

P: Foi difícil, no início dos anos setenta do século passado, uma mulher muito jovem iniciar, desenvolver e afirmar uma carreira universitária num meio tradicionalista e quase exclusivamente masculino como era o da Universidade portuguesa?

MHCC: Comecemos pelo princípio. Licencianda em 1970, eu tinha de apresentar a minha dissertação final para obter o grau de licenciada. Não podia ficar um ano sem trabalhar - e desconhecia que também para esse fim poderia gozar da bolsa da Fundação Calouste Gulbenkian, que sempre tive desde o $2^{\circ}$ ano do Liceu. Assim, concorri ao ensino secundário e fiquei colocada na Escola Preparatória da Mealhada. Parece que já antes de eu ter feito o concurso, o meu nome, atendendo às classificações obtidas ao longo do curso, fora proposto no Conselho Científico para ser Monitora da Faculdade, cargo novo que estava então a surgir, situação que eu de todo desconhecia. Leccionei então na referida Escola e quando me desvinculei em Dezembro, houve mesmo alguns problemas na minha contratação, dado que já havia completado a escolaridade da Licenciatura em História. Só a 1 de Fevereiro de 1971 entrei como Monitora na Faculdade de Letras e, note-se, para o Curso de Bibliotecários e Arquivistas, que então estava a frequentar. $O$ tempo de Monitora foi absorvido essencialmente na escrita da dissertação de licenciatura, defendida em Julho de 1971. A 2 de Dezembro de 1971 tomei posse de Assistente Eventual. E deparei-me com a primeira surpresa. Iria ser assistente não do meu orientador, o Prof. Doutor Avelino de Jesus da Costa, mas sim do Prof. Doutor Torquato de Sousa Soares, que, entretanto, regressara de Sá da Bandeira. Primeiro desafio - trabalhar com alguém que não conhecia de todo, salvo pela leitura dos seus estudos. E seria Assistente de um Professor com cerca de setenta anos de idade - completados a 7 de Março de 1973 - quando eu estava nos inícios dos 20. A minha juventude e um diferente modo de pensar e viver não foram, porém, um impedimento para uma excelente relação que mantive com este Professor, que era um Mestre que gostava de projectar os seus discípulos. Por sua mão e pela do Prof. Doutor José Sebastião da Silva Dias, fui mesmo frequentar, durante um mês, a XXI Sessão de Verão, promovida pelo "Centre d'Études Supérieures de Civilisation Médiéval de l'Université de Poitiers", assim actualizando os meus conhecimentos no estrangeiro, o que era muito raro e marcou o meu percurso. Mas cedo percebi que a presença de uma mulher assistente, a primeira a entrar no corpo docente de História na Faculdade de Letras de Coimbra, podia ser "inquietante" para muitos, dos professores aos alunos e funcionários. Tive de me situar pessoal e academicamente neste meio. No plano pessoal, continuei a ser aquela que sempre fora, uma jovem, como tantas outras daquele tempo, que gostava de trabalhar, mas também de ver cinema, ouvir música, enfim, de me divertir, e uma mulher comprometida com a sociedade, o que não poucas vezes se reverteu no epíteto de "feminista". Epíteto que assumia com orgulho, se tal quisesse dizer que pugnava por direitos iguais entre ambos os sexos, mas não renunciando à plena diferenciação dos mesmos, numa desejável complementaridade entre ambos. Mas outros pensamentos conotavam, por vezes, essa designação!... Depois, como tantas 
outras mulheres, vim a constituir uma família e a ser mãe. No plano académico pauteime por uma exigência do maior rigor e cientificidade na docência e investigação, trabalhando como melhor o sabia fazer, com todo o sentido e dedicação institucional, sendo do mesmo modo muito exigente e rigorosa para com os alunos. Creio que assim actuando, com naturalidade e coerência, e também com o apoio e solidariedade dos meus jovens Colegas, que já eram ou iam entretanto entrando para Assistentes, ganhei o meu lugar como mulher e professora, num meio académico tradicionalmente masculino. Como depois aconteceu a tantas outras Colegas que me seguiram.

P: Após várias décadas de dedicação ao ensino e à investigação da História Medieval, qual o balanço que faz da evolução da historiografia sobre a Idade Média no nosso país? Quais os pontos que considera mais positivos e quais os que considera mais negativos? 0 medievalismo português é capaz de acompanhar o passo do que de melhor se faz no plano internacional?

MHCC: O ensino e a investigação em História Medieval seguiram os caminhos da evolução do estudo e da investigação da História em Portugal. Talvez com duas especificidades. Foi um período da História sempre estudado, muito em particular até na época do Estado corporativista, ao contrário, como bem se sabe, da História Moderna mais tardia e sobretudo da Contemporânea, esta só mesmo verdadeiramente estudada depois da implantação da Democracia. Mas, devemos acentuá-lo, foi uma época histórica que teve bons professores e investigadores ao longo dos tempos. A continuidade de estudo deu-lhe, por certo, espessura científica. A escola erudita alemã contou entre nós com cultores da craveira de um Alexandre Herculano, que teve o mérito de pôr em obra a publicação dos Portugaliae Monumenta Historica, acessibilizando os documenta-monumenta, fundamentos da ciência histórica, como nos legou ainda uma História de Portugal, enformada pela base científica da investigação histórica, mas também nos deixou esse exercício outro do romance histórico e este com todos os requisitos da ficção enquadrada no ambiente histórico retratado. Essa herança, que se prolongou largamente pela primeira metade do século $\mathrm{XX}$, teve o mérito de ensinar ao medievalista uma segura metodologia no domínio de algumas ciências, como a paleografia, a diplomática, a sigilografia, a cronologia, entre outras. Em Coimbra, Avelino de Jesus da Costa, é um nome incontornável no domínio de tais saberes e no exercício da sua aplicabilidade, sobretudo nas obras que escreveu sobre a História da Arquidiocese de Braga. E a historiografia medieval não esteve totalmente fechada ao exterior, como bem o podem comprovar os estudos publicados, na década de quarenta, na Revista Portuguesa de História, que revelam conhecimentos da Escola dos Annales, os quais lentamente se iam fazendo sentir. Na década de 60 pressentem-se já os rumos da mudança e os trabalhos de A. $\mathrm{H}$. de Oliveira Marques sobre a sociedade medieval portuguesa, a introdução à história da agricultura e os seus ensaios são bem significativos, a anunciar os percursos futuros de ensino e orientação deste Mestre em estudos de história rural e urbana. Mas é claramente depois da Revolução de Abril que a tradicional história institucional e política se abre a outras tendências. Primeiro a uma história económica e social, em que o económico predominava, sendo os medievalistas muito influenciados pelo trabalho dos historiadores franceses como Marc Bloch e dos modernistas, de Braudel a Vitorino Magalhães Godinho, fixando-se na história quantitativa, mas sempre explicativa e construtiva. Depois direi que se pôs mais a tónica numa história social, em que o homem todo e todos os homens se queriam desvendar, entrecruzada com o enredo dos conceitos e métodos das demais ciências sociais, como a sociologia e a antropologia, num posicionamento interdisciplinar muito 
frutífero. Na abertura à história cultural, do pensamento e das mentalidades e à renovação temática de campos de análise, os estudos de José Mattoso serão uma bússola a orientar caminhos na história da Igreja, da religiosidade e das linhagens nobiliárquicas. E na transição do século XX para o XXI insiste-se numa abrangente história dos poderes e das elites, que beneficia da divulgação e aplicação do método prosopográfico e de diferentes enfoques da história institucional e do Direito. Em consentâneo, uma nova história militar ganhou fôlego, neste século que abriu sob o impacto da guerra.

Estas mutações nem sempre foram um devir em contínuo. Assiste-se a períodos de maior sombra na historiografia medieval portuguesa e de desfasamentos face ao que se produzia internacionalmente. Da mesma forma que os trabalhos realizados não foram, nem são, todos da mesma qualidade. Mas o balanço que faço desta evolução é positivo. Houve sempre quem "agitasse as águas" e fizesse progredir e renovar a investigação da história medieval.

Num testemunho na primeira pessoa, direi que desde cedo tive vontade de conhecer o que de melhor se ia fazendo dentro e fora do país. Por isso, logo nos inícios da minha carreira, e muito ao contrário do que era uso na Escola de Coimbra, eu passei a frequentar reuniões científicas nacionais e estrangeiras. Percebia claramente como tais encontros me davam o ensejo de aproveitar com o saber dos Mestres e de acompanhar a evolução da historiografia internacional. E esforcei-me por compaginar a minha produção científica com os novos campos historiográficos que se foram abrindo a nível internacional da mesma forma que procurei investi-los reprodutivamente na minha pedagogia e na investigação dos trabalhos académicos que orientei.

E aqui estamos já a dar passagem às outras interrogações que me coloca, passando para a avaliação do presente, o que é bem mais difícil. Mas claramente lhe direi que estou também optimista, embora, como penso, atenta ao que se produz. Logo, parece-me que se está a involuir um tanto para a elaboração de estudos assentes na apresentação de fontes, seja de que natureza forem, com pouca reflexão e construção histórica. E pergunto-me: uma avaliação dos Currículos, que parece ter muito em conta a bibliometria, não estará em grande parte a contribuir para a composição deste pior cenário? A ânsia ou a exigência de marcar presença em reuniões científicas - que me parecem estar a ter lugar em número excessivo, pelo menos em Portugal - e de contar com várias publicações em revistas não permite, por vezes, uma investigação mais aprofundada e uma maturação reflexiva das temáticas abordadas. Para mais a nossa carência de debates críticos e abertos também não ajuda. Todavia, deverei assinalar que foram os mais jovens a promover encontros de debates de dissertações de mestrado, teses de doutoramento e outras, que me parecem da maior oportunidade e valia. Do mesmo modo, sabemos que a historiografia portuguesa não é muito voltada para a teorização, e os medievalistas não fogem a essa regra, ainda que tal situação devesse ser revertida. Num outro sentido, entendo ser vantajoso que os medievalistas portugueses entrem decididamente pela investigação e estudo de temáticas fora do contexto e da espacialidade do reino de Portugal, não temendo estudar a história de outros reinos da Europa ou até de outros continentes. Creio que esta poderá ser mesmo uma via de atrair os olhares dos outros sobre os historiadores portugueses e sobre a História de Portugal e fomentar, mais intensamente, uma história comparativa. O cruzamento interdisciplinar na abordagem histórica, julgo que continua a ser um percurso muito perseguido pelos medievalistas, mais numas Escolas que noutras, é certo, o que será 
sempre uma mais valia. Deixarei ainda um reparo e um incentivo - o de se escrever num português claro e elegante. E tal não vem acontecendo, já que os mais jovens têm uma cada vez maior dificuldade em se exprimir num português correcto e limpo, desde logo na oralidade, mas sobretudo na escrita. Quando chegam ao Ensino Superior com esta deficiência, terão de a colmatar lendo, lendo muito, lendo boas obras de literatura portuguesa ou, no caso de traduções, assegurando-se que elas são de qualidade.

Por outro lado, verifico que, muito assinalavelmente, e até por força dos imperativos da avaliação, ao insistir na internacionalização, os jovens participam com assiduidade em reuniões científicas internacionais. Fazem-no comunicando, e bem, maioritariamente em inglês, e seguindo as propostas de uma historiografia anglo-saxónica. Todavia, seria desejável que dominassem mais línguas estrangeiras, como o francês, para terem acesso à historiografia francesa, tão importante no fundamento do pensamento histórico científico, ou o alemão, e cada vez mais se predispusessem a trabalhar com a bibliografia italiana ou espanhola, e logo desde a licenciatura, já que estas línguas não são difíceis de entender para quem utiliza como veículo de expressão uma língua românica. Só este esforço no sentido de ampliarem o seu domínio de línguas estrangeiras lhes permitirá uma mais abrangente e complexa rede de inserção em diferentes correntes historiográficas. A finalizar, e respondendo à sua última pergunta, direi que considero que o medievalismo português acompanha o panorama da historiografia internacional. Todo, em parte, ao mesmo ritmo? Isso é mesmo muito difícil de avaliar. Mas inequivocamente, quando estou presente num Congresso internacional, no geral, congratulo-me com as prestações científicas dos nossos medievalistas. Peço-lhes, no entanto, que se sintam sempre inquietos com o que fazem e interpelados pelo que de melhor os outros fizeram para experimentarem o estímulo interior e pessoal de desejarem ir sempre mais além.

P: E quanto ao ensino universitário, especialmente ao da História e da História Medieval? Quais os aspectos melhores e quais os piores que tem encontrado? Considera que a História da Idade Média, na acepção mais tradicional da disciplina, tem sabido relacionarse com outras áreas de especialidade como a arqueologia, a história da arte, a literatura, a antropologia...?

MHCC: Actualmente os Cursos de História, como outros de Ciências Humanas, estão muito vocacionados para uma grande abertura científica e combinação transdisciplinar. A exigir um regime tutorial muito dinâmico e que se empenhe mesmo em conhecer os estudantes para os aconselhar, de acordo aos seus gostos e competências, e para os acompanhar ao longo de todo o Curso ou mesmo da vida. Estas combinatórias colocam ainda mais desafios ao ensino da História e, concretamente, da História Medieval. Numa licenciatura, creio que se torna fundamental que os alunos saibam o que é a História e com que fontes e metodologias se constrói o saber histórico. Depois, na leccionação, o docente de História da Idade Média Geral ou de Portugal sabe que não poderá abarcar os mil anos que o seu período histórico abrange. Terá portanto de ensinar de acordo com os critérios que considera mais operativos para sua apreensão - evolução diacrónica? total? parcial? enfoque mais político, económico ou social? temas? - e penso que aqui não há programas "obrigatórios" ou mesmo "modelares". Será apenas desejável que o que for leccionado o seja com rigor, com recurso à bibliografia mais actualizada e pertinente, com sentido crítico, de tal modo que o estudante possa depois, por si mesmo, estudar qualquer período, acontecimento ou temática. Parece-me, no entanto, fundamental que logo na licenciatura haja um seminário que inicie os estudantes na investigação, pondo-os em contacto com a crítica das fontes, e que os 
motive para o questionamento das mesmas e para a reflexão histórica. Se, porventura, ao longo da licenciatura, os tutores se aperceberem da vocação do estudante pela época medieval deveriam aconselhá-lo a frequentar algumas disciplinas que lhe são muito úteis, da paleografia e diplomática ao latim, mas também outras das áreas que mencionou de arqueologia, história de arte, literatura, antropologia, sociologia ou direito. Este relacionamento entre a História e as diferentes áreas do saber pode e deve ser intensificado. E, por vezes, nem mesmo nas áreas disciplinares que estão bem próximas, como a história de arte ou arqueologia, são postas em prática. Em seguida, nos demais graus de ensino - $2^{\circ}$ Ciclo e $3^{\circ}$ Ciclo - creio que se deve insistir essencialmente no saber fazer História e menos no saber aprender História. Há que privilegiar o trabalho do aluno com orientação do professor, levando-o a desenvolver um sentido crítico, a conhecer e a recorrer a todo o tipo de fontes, a saber interrogar coerentemente e com novidade as mesmas face ao objectivo do tema a investigar, e a apresentar uma elaboração histórica rigorosa, clara e coesa, de um texto oral ou escrito.

P: A Idade Média, tantas vezes vista como uma época de "barbárie e obscurantismo", tem vindo a suscitar alguma curiosidade e mesmo simpatia entre públicos não especializados. As "utilizações" da época medieval são cada vez mais frequentes entre nós, por exemplo em feiras e mercados ou em torneios "medievais". Que reflexões Ihe merecem estes tipos de utilizações?

MHCC: Primeiro, muito desejaria que já estivesse plenamente erradicada a visão retrógrada e errónea da Idade Média como uma época de "barbárie e obscurantismo". E infelizmente verifico que ainda se encontram muitas dessas desastrosas afirmações, e pior ainda, interiorizações, mesmo entre pessoas letradas e cultas. Mas se temos de carregar o peso dessa visão "negra" projetada pelos humanistas sobre a Idade Média, também somos herdeiros de uma visão nostálgica e pitoresca do romantismo, que desenvolveu um gosto pelas tradições medievais, pelos romances de cavalaria, pela cultura folclórica e que buscava na época medieval as lendas e mitologias germânicas. E creio que é ainda com este mesmo sentido, com um desejo do exótico e de uma procura das origens, a par do fascínio pelas reconstituições históricas, que se põem em cena feiras, mercados, ceias ou torneios medievais. Como sabe, eu estive à frente da reconstituição da feira medieval de Coimbra, em 1992, talvez a primeira a realizar-se no nosso país. E fi-lo com toda a consciência dos perigos e desafios que tal empresa envolvia. Mobilizei-me, então, para ensinar os grupos que encenavam a feira, transmitindo-lhes conhecimentos sobre o tema em sessões mensais muito vivas e participadas. Esta primeira feira de Coimbra, e talvez ainda a segunda, correram muito bem. Depois deixaram de ser respeitadas as condições indispensáveis de verosimilhança e eu, inevitavelmente, tive de me afastar. Na verdade, se queremos reconstituir uma época e uma actividade, temos de saber do que tratamos e trabalhar com rigor e com um sentido de historicidade. Só assim esses eventos poderiam ser didácticos, captando o público para a História, e, mais ainda, para a época medieval, que se representa. Tal não acontecendo, como na maior parte dos casos actualmente, essas reconstituições não prestam um bom serviço à medievalidade, apelando apenas à diversão e ao negócio e transmitindo mesmo mensagens históricas erróneas. Mas vemo-las por toda a parte na Península Ibérica. E talvez mesmo em crescendo, quando os regionalismos se reivindicam dos foros e costumes medievais para reclamarem a sua especificidade e, mais ainda, a sua independência.

P: Num outro plano, várias entidades locais têm procurado recuperar e valorizar elementos do que consideram o seu património colectivo, com destaque também para tudo o que 
remonta à época medieval. Referimo-nos não apenas aos monumentos (castelos, igrejas, mosteiros...), mas também, por exemplo, à edição de documentos como as cartas de foral, publicadas geralmente através da iniciativa de autarquias que nisso procuram um elevado rigor quanto ao respectivo conteúdo e um grande cuidado na apresentação gráfica. Como interpretar este interesse? A época medieval é vista como uma época fundadora das identidades e das especificidades locais ou regionais?

MHCC: Retomamos o tema anterior. Sim, inequivocamente, e sobretudo em Espanha, a época medieval é vista, sobretudo pelos políticos, como uma época fundadora das identidades e dos particularismos locais ou regionais. Nós bem sabemos como a História, pouco estudada e relegada para o esquecimento nos diversos graus de ensino, é aproveitada pelos políticos e pelos poderes quando tal lhes interessa. Mas julgo ser possível afirmar que em Portugal, sem regiões que reclamem a independência, o empenho das autarquias vai mais no sentido de pretenderem conhecer o seu passado histórico com vista a um maior aprofundamento das suas raízes, cimentadoras das suas identidades. Esta é a minha convicção, certa ou errada, não sei. Talvez acredite nela, porque muito me esforcei por dotar as autarquias de técnicos com formação científica que as apoiassem na sua política cultural. O Curso de Especialização em Assuntos Culturais no Âmbito das Autarquias, que funcionou na Faculdade de Letras de Coimbra de 1989 a 2004, em parceria com o Centro de Estudos e Formação Autárquica, e depois a sua reestruturação em $2^{\circ}$ Ciclo de Política Cultural Autárquica, que desde 2007 abre bianualmente, foram cursos pioneiros, criados por mim e pelo Doutor José d'Encarnação, e de que sempre fui Coordenadora, os quais pretenderam e pretendem justamente fornecer conhecimentos de "banda larga" em história, arquivos, bibliotecas, direito, finanças, comunicação social e criação artística para habilitar os que os frequentam a saber gizar e pôr em prática projetos e realizações sócio-culturais. Acredito que a presença de técnicos licenciados em História ou ciências afins, e alguns deles com esta Especialização ou Mestrado, esteja a dar bons frutos. Como afirmou, as obras publicadas pelas autarquias são de "elevado rigor" e "cuidada apresentação gráfica". De facto, as autarquias têm-se aproximado das Universidades e trabalhado com os historiadores - sendo esse o caminho correcto a perseguir -, e, no caso vertente, com os diversos especialistas da época medieval, o que é extraordinariamente louvável. Julgo que a maioria dos dirigentes autárquicos partilha já da opinião que a História deve ser tratada por historiadores. Da mesma forma que estou convicta que o poder local quer conhecer o seu passado histórico e preservar e divulgar o seu património, como um meio de fundamentar a identidade e coesão dos seus munícipes, com vista a fomentar uma cidadania mais comprometida e activa em prol da comunidade, e perseguindo uma saudável política de valorizar cultural e economicamente e dar a conhecer a sua terra e região.

P: Sendo os arquivos históricos lugares quase inevitáveis para o trabalho de quem investiga sobre a época medieval, debatemo-nos muitas vezes com a contradição entre a obrigação de preservar um património documental com centenas de anos e a necessidade de ter acesso a esses mesmos documentos. É frequente ouvir-se que os arquivistas privilegiam a conservação (tempos houve em que foram mesmo designados "conservadores"...) e que aos investigadores só interessa poderem aceder sem limites à documentação. Postas assim as coisas, estamos, evidentemente, perante uma caricatura; mas como conjugar estas duas "urgências"? Como fazer convergir, neste ponto, arquivistas e historiadores?

MHCC: Como diz, e muito bem, as funções do arquivista e do historiador são diferentes, mas não devem ser dicotómicas, antes complementares. De facto, aos arquivistas 
compete a meritória tarefa de preservar a documentação, mas igualmente de a tratar inventariando, catalogando, sumariando - e de a acessibilizar ao público. Aos historiadores cumpre estudar os documentos, mas ao mesmo tempo respeitar o património documental. Compreende-se, por isso, que hoje se recorra a técnicas de digitalização ou reprodução dos documentos, que os preservam dos estragos do seu contínuo manuseamento. Mas tal exige que, correlativamente, existam bons meios de divulgação e de acessibilidade de leitura dessas reproduções. Em paralelo, a política nacional dos arquivos deve ter como objectivo a conservação do seu espólio, ónus que não se deve transferir para o utilizador. Não se compreende que, em certos casos, se pretenda que seja o investigador a arcar com os custos da conservação ou restauração das espécies documentais, quando as pretende reproduzir. o património documental é de todo um país e, portanto, a todos os cidadãos, através dos impostos que pagam, compete a sua manutenção. $O$ investigador terá de suportar os custos das reproduções que requer, e apenas dessas, dentro de um preçário justo e acessível, que não seja ditado por uma lógica de lucro. Do mesmo modo haverá que fazer os possíveis para que o tempo previsto entre o pedido e a sua concretização seja razoável e não excessivamente arrastado no tempo. Igualmente os arquivistas devem fornecer todas as informações requeridas pelo público utente, da mesma forma que o investigador tem de ser colaborante e pôr mesmo ao dispor do arquivo o resultado do seu labor com as fontes nele consultadas. E para bem de toda a comunidade, será muito importante reclamar que os arquivos insistam numa política de digitalização e acessibilização online do seu espólio, o que requer, inevitavelmente, um maior financiamento estatal para os Arquivos e Bibliotecas.

P: O que considera que será mais importante dizer aos jovens universitários que se interessam por História da Idade Média, num contexto que não é muito auspicioso para quem queira enveredar pela investigação?

E que balanço se pode fazer da política da FCT ao longo destes últimos anos, no que respeita a opções de financiamento (bases de dados versus edição de fontes; livros versus publicações electrónicas), à estrutura, avaliação e financiamento das Unidades de Investigação, à composição e funcionamento dos júris (das Ul's e dos concursos de bolsas)?

MHCC: Isso não é uma pergunta. É uma "bateria" de perguntas! Comecemos pelos jovens, pois são eles que devem merecer a nossa melhor atenção. E neste particular haverá a considerar várias situações. Mas, em qualquer delas, só queria transmitir que se devem munir das melhores ferramentas possíveis para a investigação histórica que, em rigor metodológico e conceptual, é igual para qualquer época, se bem que a medievalidade exija acrescidos saberes paleográficos, diplomáticos e afins, além de, em muitos casos, conhecimentos de latim e, noutros, de grego ou árabe. Se porventura se encontram a elaborar uma tese de doutoramento, deverão, como é evidente, concorrer ao programa de bolsas da FCT, ainda que, infelizmente, tais bolsas sejam em escasso número. Encontrando-se numa fase de pós-doutoramento, o percurso do medievalista, como de qualquer outro historiador, parece ser mais estreito, cabendo-lhe concorrer a projectos de investigação. Neste particular, creio que teremos de ser ainda mais dinâmicos na elaboração e submissão de projectos que captem financiamento europeu, embora eu saiba bem como tal trabalho exige apoios e competências técnicas informáticas de que muitas vezes os investigadores não dispõem nos Centros ou nas Faculdades para levarem a efeito essas propostas de projectos. Além disso, penso que devem, e todos devemos, batalhar por uma carreira de investigação, que seja de facto 
uma realidade, capaz de integrar os jovens altamente qualificados que ajudámos a formar, e não uma quimera como a que se gizou. Se porventura estamos a falar de um aluno que gosta de História de Idade Média, ou mais amplamente de História, não sabendo se vai ou não prolongar os seus estudos neste campo do saber, aconselhava-o a realizar um Curso com as maiores aberturas disciplinares e a entrecruzar o saber histórico com as competências informáticas, com o domínio de várias línguas e com algumas áreas científicas diferentes do seu particular interesse. Na verdade, o conhecimento histórico poderá servir-lhe como uma ferramenta para a melhor apreensão da realidade económica, social e política do presente, a investir em diversas actividades laborais, que se lhe possam apresentar.

Vejamos agora o caso da FCT. Comecemos talvez do mais amplo para o mais restrito, portanto pelas Unidades de Investigação. Torna-se inquestionável que no actual panorama são elas que sustentam a investigação em Portugal e também parece claro que um Ensino Superior sem investigação não é um Ensino Superior. Dizendo apenas isto, não estou a advogar que se tem de sancionar qualquer UI universitária, mas a política científica deve ir no sentido de apoiar as que são credíveis, bem como incentivar à reformulação as que não cumpram os objectivos desejados, o que pode exigir mesmo fusões para ganharem escala. Não me parece que se devam fomentar grandes disparidades entre as UI - salvo perante casos verdadeiramente excepcionais mas antes distribuir mais equilibradamente as verbas. A tempo, e com toda a clareza, terão de ser conhecidos os critérios (e revistos muitos deles desde a bibliometria à hegemonia da difusão do saber em língua inglesa) e normativas da avaliação das UI. Em seguida, os júris que as avaliam deveriam integrar sempre um investigador português, pois ele seria o penhor do conhecimento das estruturas universitárias portuguesas em que as UI se inserem, e os investigadores estrangeiros teriam, obrigatoriamente, de saber ler o português, a nossa língua materna e uma língua de dimensão global. A internacionalização não tem que ser feita apenas em inglês, esse terá de ser um dogma a rever, mas igualmente em francês, alemão, italiano, espanhol ou português. Para os júris das bolsas de doutoramento ou pós-doutoramento reclama-se a mais ampla integração de docentes e investigadores de diversas instituições de Ensino Superior e um total descomprometimento dos avaliadores face aos avaliados para que possa haver isenção e limpidez no julgamento científico. Quanto a opções de financiamento, o que nos levaria para a discussão dos critérios de avaliação, a merecer um debate aberto, frontal e objectivo, em que se tenha em conta a compatibilização da avaliação com a diversidade das áreas científicas, pronuncio-me apenas pelos casos que me aponta. Sou totalmente a favor de publicações electrónicas, se tal não for redutor. A publicação electrónica não é incompatível com a divulgação em papel e, para cada caso, haverá que avaliar a melhor hipótese. A política da livre e aberta acessibilização dos resultados das publicações parece-me fundamental e muito enriquecedora. Igualmente não vejo dicotomia entre as bases de dados e as edições de fontes. Mas como foram estas últimas as anatematizadas, comecemos por estas. Todos sabem que sou plenamente a favor das edições críticas de fontes. Sinto até uma certa inferioridade ao dizer que as chancelarias e cortes medievais portuguesas não estão ainda publicadas, a par de tanta outra documentação importantíssima de diversas entidades produtoras. Sou mesmo defensora de criteriosas edições críticas de fontes, que apenas apresentem um adequado estudo diplomático das mesmas, e não qualquer estudo histórico. A edição crítica documental é um meticuloso e científico labor, que deve ser levado a cabo por 
especialistas, e que fica depois ao serviço de toda a comunidade científica. E servi-laiam tanto melhor quanto, a par das edições em papel, pudessem estar acessíveis online. As bases de dados são um outro material de trabalho, ainda que, no geral, mais parcial. $\mathrm{Na}$ verdade, muitas delas foram elaboradas de acordo com os critérios do projecto de investigação em que se inseriam e não têm por isso a "universalidade" das publicações documentais. Mas são, sem dúvida, utilíssimas. Devem, no entanto, no final de cada projecto, ser disponibilizadas ao público em geral para que possam ser utilizadas por todos os historiadores que delas necessitem. Penso até que, para muitos assuntos da história medieval, em que não há fontes directas, mas podemos colher informação em qualquer uma, como preços, por exemplo, poderia haver bases de dados em construção, que os medievalistas pudessem ir preenchendo com os contributos da sua investigação específica. Mais do que nunca devemos trabalhar em rede e em intercomunicação. E, por fim, desejava formular um voto de que a investigação, muito em particular nas ciências sociais e humanas, tivesse um financiamento reforçado, dado que elas contribuem, como as demais ciências, para o aprofundamento do conhecimento que é sempre um investimento reprodutivo, social e economicamente, muito mais quando o património e a cultura estão a ser mobilizados pelo turismo, que, no momento, é uma âncora do nosso desenvolvimento económico.

P: Além de autora de uma obra considerada como referência fundamental na historiografia portuguesa, a Professora Maria Helena da Cruz Coelho tem-se mantido como uma figura muito respeitada e admirada, mas também singularmente consensual entre os medievalistas portugueses. A postura institucional que a tem caracterizado, evitando ou atenuando atitudes críticas em tomadas de posição públicas, ajuda a explicar essa que é uma situação pessoal pouco comum?

MHCC: A afirmação da minha consensualidade entre os medievalistas portugueses é do entrevistador. Quanto à pergunta, é de difícil resposta. Desde logo porque não me parece que o consenso não corra a par com um espírito crítico e interventivo. Acredito que é com o diálogo, com debates abertos, francos e frontais, que se podem articular ideias e actos. Sempre procurei conhecer a opinião dos outros, mas não deixei de expressar e pugnar pela minha. Os que exprimiam ideias contrárias às que defendia mereceram-me sempre o maior respeito. Assumi, não poucas vezes, posições críticas e tomei posições públicas de acordo com o conhecimento mais abrangente possível do assunto em debate e os imperativos da minha consciência. Entretanto, na minha vida académica, trabalhei com muitas Escolas para além da minha de Coimbra e com Mestres dessas instituições. Tal relacionamento deu-me, desde muito cedo, uma abertura comparativa e uma capacidade de lidar consensualmente com historiadores de formações distintas e personalidades próprias. No Porto fui extraordinariamente apoiada pelo Doutor Baquero Moreno e através dele conheci toda a medievalidade (e não só) das Universidades do Porto e do Minho e os mais relevantes medievalistas ibéricos de então. Em Lisboa tive como meu orientador de Doutoramento o Doutor A. H. de Oliveira Marques, que me abriu o espírito para o vasto mundo do relacionamento entre os historiadores pela sua experiência docente e de investigação na Alemanha, nos Estados Unidos e em Portugal e me deu ensejo de conhecer a cultura urbana lisboeta. Mas, como é bem sabido, não deixei de ter contactos científicos e pessoais com tantos outros historiadores de diversas pensamentos e Escolas, como José Mattoso, Joaquim Veríssimo Serrão, Jorge Borges de Macedo, António Borges Coelho, entre muitos mais da minha geração. Acresce que, pelo facto de ter sido a única Doutora em Coimbra durante alguns anos, era convidada para integrar quase todos os júris de História 
Medieval, quando a regra era a presença nos mesmos de, pelo menos, dois Doutores exteriores à instituição onde se realizavam as provas. E depois, nos meus longos 45 anos de carreira, continuei a participar em provas públicas académicas e em concursos - e já conto com mais de 270 - o que me permitiu ter um quadro muito abrangente do saber histórico desenvolvido em várias Escolas e por muitos medievalistas e de exercitar largamente o meu espírito crítico, ainda que sempre em permanente diálogo. Não menos partilhei com Colegas o exercício científico e responsabilizante da avaliação, e insisto, sempre com um espírito construtivo de apelar à melhoria e reformulação, quando integrei, em 1998-1999, a primeira Comissão da Avaliação Externa dos Cursos de História e, de 2012 a 2014, fui, a convite da Agência de Acreditação e Avaliação do Ensino Superior, Membro da Comissão de Avaliação Externa dos Cursos de História, Arqueologia e Património, ou quando integrei os Painéis de Avaliação da Fundação para a Ciência e Tecnologia para analisar as candidaturas a bolsas de Mestrado, Doutoramento e Pós-Doutoramento em História e Arqueologia. Aliás, o espírito crítico, mas não menos o consensual, faz hoje parte integrante das nossas funções, quando aceitamos fazer parte de Comissões Científicas de Congressos ou da Direcção, Coordenação ou Corpo Científico de uma revista. Os medievalistas constituem um grupo pequeno dentro do conjunto dos historiadores, com problemas específicos, no âmbito dos já muitos que a História enfrenta no contexto das ciências humanas e sociais. Deveremos, mais do que nunca, trabalhar em conjunto, num permanente debate pelo fazer, desfazer e refazer o conhecimento histórico. Eu continuarei a querer dialogar e a colaborar, enquanto me for possível, com todos os que acreditem que poderemos estar a dignificar a História e muito em particular a História Medieval. 